\title{
The Potential Predictive Value of Preoperative Brain Natriuretic Peptide Levels in Coronary Artery Bypass Grafting Surgery
}

\author{
Konstantinos Tziomalos ${ }^{*}$, , Julia Sevastidou ${ }^{1,2}$, Antonios A. Pitsis ${ }^{2}$, Asterios Karagiannis ${ }^{1}$, \\ Georgios Kyriazis $^{3}$, Margarita Kataropoulou ${ }^{3}$, Aikaterini Mpalaska ${ }^{1}$, Vasilios G. Athyros ${ }^{1}$ \\ and Elias Basayannis ${ }^{1}$
}

\author{
${ }^{1}$ Second Propedeutic Department of Internal Medicine, Aristotle University of Thessaloniki, Hippokration Hospital, \\ ${ }^{2}$ Thessaloniki Heart Institute, St. Luke's Hospital, ${ }^{3}$ Laboratory of Immunology, Department of Pulmonary Diseases, Ar- \\ istotle University of Thessaloniki, “Georgios Papanikolaou” Hospital, Thessaloniki, Greece
}

\begin{abstract}
Aims: The aim of this study was to assess whether preoperative and postoperative brain natriuretic peptide (BNP) levels could be used as predictors of postoperative complications and outcome in patients with coronary artery disease and ischemic heart failure undergoing on-pump or off-pump coronary artery bypass grafting surgery (CABG).

Methods and Results: Fifty-eight patients (56 males and two females) with a median age of $65.3 \pm 9.9$ years were included in the study. Thirty-eight patients $(65.5 \%)$ underwent on-pump CABG, and 20 patients (34.5\%) underwent off-pump CABG. BNP levels were determined within 24 hours before CABG and serially at 6 hours, 24 hours, 3, 7 and 30 days after CABG. Creatine phosphokinase myocardial band (CK-MB) levels were measured 1, 3, and 7 days after CABG. BNP and CK-MB levels did not differ significantly between the two groups at any time point. Preoperative BNP levels independently predicted the occurrence of cardiogenic shock and more importantly, short-term mortality. Neither preoperative left ventricular ejection fraction nor postoperative BNP or CK-MB levels at any time point showed any significant independent prognostic value for any postoperative complication. Conclusion: Our results suggest that it may be prudent to more closely monitor patients with higher preoperative BNP levels for possible postoperative complications.
\end{abstract}

Keywords: Brain natriuretic peptide, coronary artery bypass grafting surgery, coronary artery disease, ischemic heart failure, prognosis, off-pump coronary artery bypass grafting surgery.

\section{INTRODUCTION}

Coronary artery bypass grafting surgery (CABG) is one of the most effective therapies for coronary artery disease (CAD). CABG is conventionally performed with the use of cardiopulmonary bypass (CPB). Nevertheless, CPB has been associated with an increased frequency of complications [16]. CABG without using extra-corporeal circulation eliminates $\mathrm{CPB}$ to accomplish $\mathrm{CABG}$ and recent randomized studies comparing on- and off-pump procedures showed comparable cardiac outcome [7-11] and decreased morbidity and mortality in off-pump CABG patients [6-13].

However, morbidity associated with CABG is still a matter of concern. A variety of risk factors have been described to help delineate risk assessment of patients undergoing CABG, including preoperative left ventricular ejection fraction (LVEF) $[14,15]$ and postoperative increase in creatine phosphokinase myocardial band (CK-MB) levels [16-22]. However, no gold standard to effectively predict postoperative complications currently exists [23]. A valuable addition to the preoperative evaluation would be a quantitative, costeffective, time-efficient serum marker capable of accurately predicting postoperative morbidity and mortality.

*Address correspondence to this author at the Second Propedeutic Department of Internal Medicine, Aristotle University of Thessaloniki, Hippokration Hospital, 63 Solonos Street, Thessaloniki, 54248, Greece; Tel: +302310823487; Fax: +302310992834; E-mail: ktziomalos@yahoo.com
Brain natriuretic peptide (BNP) is a 32-amino acid peptide primarily synthesized in the cardiac ventricle and is being released in response to ventricular dilatation and pressure overload $[24,25]$. Since BNP accurately identifies LV dysfunction [26-29], BNP measurement might be useful in risk stratification of patients undergoing CABG. However, there is a paucity of data regarding the predictive value of BNP in this setting, especially in off-pump CABG [15,23,30-35].

The aim of this study was to determine the secretion pattern of BNP in patients with CAD and ischemic heart failure undergoing on-pump or off-pump CABG and to assess whether preoperative and postoperative BNP levels could be used as predictors of postoperative complications and outcome.

\section{PATIENTS AND METHODOLOGY}

This prospective study included consecutive patients with angiographically verified CAD referred for elective CABG. In addition, all patients had LV systolic impairment measured by ventriculography or echocardiographic examination.

At baseline, demographic data (age, sex), history of conventional vascular risk factors (hypertension, diabetes mellitus, hyperlipidemia, smoking habit, alcohol abuse), and of atrial fibrillation, chronic obstructive pulmonary disease (COPD) and chronic kidney disease were obtained. Hyperlipidemia was defined as low-density lipoprotein cholesterol $(\mathrm{LDL}-\mathrm{C})>100 \mathrm{mg} / \mathrm{dl}$ or treatment with lipid-lowering medi- 
cation. Chronic kidney disease was defined as creatinine clearance $<60 \mathrm{ml} / \mathrm{min} / 1.73 \mathrm{~m}^{2}[36]$.

We determined heart rate, systolic and diastolic arterial blood pressure, and heart failure status according to New York Heart Association (NYHA). Routine laboratory investigations were performed the first day after admission to the hospital after overnight fasting, and included levels of glucose, total cholesterol, high-density lipoprotein cholesterol (HDL-C), triglycerides, urea, creatinine, uric acid, fibrinogen, hemoglobin, and hematocrit. All laboratory tests were performed on a Roche/Hitachi 912 analyzer (Roche Diagnostics GmbH, Mannheim, Germany). LDL-C was calculated using Friedewald's formula [37]. Preoperative renal function was assessed by baseline creatinine clearance, calculated by the Modification of Diet in Renal Disease equation [36]. CK-MB was measured 1, 3, and 7 days after surgery using a Roche/Hitachi 912 analyzer (Roche Diagnostics GmbH, Mannheim, Germany)(normal range < 24 IU/l).

Blood samples for BNP measurement were obtained within 24 hours before surgery and serially at 6 hours, 24 hours, 3, 7 and 30 days after the operation. Blood samples for BNP were taken into EDTA tubes in which $250 \mu$ of aprotinin had been added to inhibit breakdown of the hormone. All samples were centrifuged immediately after collection at 2000 turns for $20 \mathrm{~min}$ and were stored at $-80^{\circ} \mathrm{C}$ until analyzed. BNP concentration was determined by a competitive enzyme-linked immunosorbent assay (ELISA) in 96-well microtiter plates (micro-ELISA) [38,39]. All reagents and materials were supplied by Peninsula Laboratories Inc., CA, USA. The minimum detectable BNP concentration of the assay is $0.06 \mathrm{ng} / \mathrm{mL}$ and the intra-assay and inter-assay coefficient of variation were $5 \%$ and $14 \%$ respectively.

All patients were submitted preoperatively to comprehensive echocardiography (EnVisor C Ultrasound System, Philips Medical Systems, Eindhoven, Netherlands). Measurements included interventricular septal thickness (IVS), posterior wall thickness (PW), LV diameter at end-diastole (LVDd), and right ventricular diameter at end-diastole. LVEF was calculated according to the Teichholz equations [40]. Echocardiography was repeated when clinically indicated and in all patients on the $7^{\text {th }}$ day post-CABG and at a follow-up visit on the $30^{\text {th }}$ day post-operatively.

Left-heart catheterization was performed preoperatively in all patients. We measured LVEF, systemic and pulmonary vascular resistance, central venous pressure, pulmonary capillary wedge pressure, pulmonary arterial systolic pressure, left and right ventricular stroke work index, stroke volume and stroke volume index. Cardiac output was measured by the thermodilution method, and cardiac index was calculated.

The same surgeon operated on all patients. On-pump $\mathrm{CABG}$ was carried out with normothermic $\left(37^{\circ} \mathrm{C}\right) \mathrm{CPB}$ using intermittent antegrade hyperkalaemic warm blood cardioplegia supplemented with magnesium [41]. During off-pump procedures, a stabilizer (Koros Surgical Instruments, Moorpark, CA, USA) was used to expose and stabilize the target coronary artery. The left internal thoracic artery was anastomosed to the left anterior descending artery, and the right internal thoracic artery, radial artery and/or saphenous vein graft were used for other lesions [42].
Both intraoperatively and postoperatively - until exit from the hospital - we monitored and recorded the occurrence of myocardial infarction, cardiac enzyme elevation, malignant arrhythmias, emergency reintubation, hemodynamic instability requiring inotropic support, cardiogenic shock, requirement for intraaortic balloon counterpulsation, acute respiratory failure, acute renal failure requiring dialysis, and pleural infusion. We also recorded duration of ventilator dependence, intensive care unit (ICU) length of stay, and total hospital length of stay, as well as readmission within 30 days for cardiac reasons, and mortality and cause of death within 30 days postoperatively. Diagnosis of myocardial infarction was based on ECG changes (new persistent Q waves and ST segment deviations: $1 \mathrm{mV} \mathrm{ST}$ segment increases in $\geq 2$ limb leads and/or $2 \mathrm{mV}$ ST segment increases in $\geq 2$ precordial leads), and an increase in serum CKMB levels ten times over the upper limit of normal range.

All patients gave written informed consent before study entry. The study was conducted in accordance with the Declaration of Helsinki.

All data were analyzed using the statistical package SPSS (version 10.0; SPSS Inc., Chicago, IL). Continuous data are presented as mean \pm SD and categorical data as absolute numbers and percentages. Because BNP values were not normally distributed, they were logarithmically transformed for statistical analysis, but are presented in the study as non-transformed median and range. Correlations between variables were assessed using Pearson's correlation. The Student's t-test and chi-square test were used for comparisons of continuous and categorical variables between groups respectively. The significance of changes in LVEF and BNP before and after operation was evaluated with analysis of variance (ANOVA) for repeated measures. In addition, the variation over time of $\mathrm{BNP}$ was analyzed according to the type of CABG using analysis of covariance (ANCOVA). The predictive value of BNP concentrations and other relevant variables for intra- and postoperative complications was assessed by use of logistic regression, including all variables that predicted complications in univariate analysis. Odds ratios (OR) were generated and expressed with $95 \%$ confidence intervals (CI). The utility of BNP as a prognostic indicator of intraoperative and postoperative complications was also evaluated using receiver operating characteristic (ROC) curves. In all cases, a 2-tailed $p$ value less than 0.05 was considered statistically significant.

\section{RESULTS}

Fifty-eight patients (56 males and two females) with a median age of $65.3 \pm 9.9$ years were included in the study. Thirtyeight patients $(65.5 \%)$ underwent on-pump CABG, and 20 patients $(34.5 \%)$ underwent off-pump CABG. Preoperative patient characteristics are presented in Tables $\mathbf{1}$ and $\mathbf{2}$. Preoperatively, patients who underwent on-pump CABG were significantly younger $(\mathrm{p}=0.038)$, had lower systolic blood pressure $(p=0.005)$, lower diastolic blood pressure $(p=0.034)$, and higher uric acid levels $(\mathrm{p}=0.043)$. In addition, the former had a lower number of diseased vessels $(\mathrm{p}=0.005)$ and significantly greater cardiac output $(\mathrm{p}=0.007)$ compared with patients who underwent off-pump CABG.

Median preoperative BNP concentration was $1.0 \mathrm{ng} / \mathrm{ml}$ (range, 0.1-64.2 ng/ml). BNP correlated significantly with age $(\mathrm{r}=0.342, \mathrm{p}=0.009)$, creatinine clearance $(\mathrm{r}=-0.303$, 
Table 1. Demographics, Vascular Risk Factors and Vascular Diseases of the Study Population

\begin{tabular}{|c|c|c|c|c|}
\hline Parameter & $\underset{(n=38)}{\text { On-Pump CABG }}$ & $\begin{array}{c}\text { Off-Pump CABG } \\
(n=20)\end{array}$ & $\mathbf{p}^{*}$ & Overall $(n=58)$ \\
\hline Age (years) & $63.4 \pm 8.9$ & $69.0 \pm 10.7$ & 0.038 & $65.3 \pm 9.9$ \\
\hline Males (\%) & 94.7 & 100.0 & 0.77 & 96.6 \\
\hline Hypertension (\%) & 65.8 & 80.0 & 0.41 & 70.7 \\
\hline Diabetes mellitus (\%) & 28.9 & 30.0 & 1.00 & 29.3 \\
\hline Atrial fibrillation (\%) & 13.2 & 10.0 & 1.00 & 12.1 \\
\hline $\begin{array}{l}\text { Previous percutaneous transluminal coronary angioplasty } \\
(\%)\end{array}$ & 2.6 & 10.0 & 0.56 & 5.2 \\
\hline Previous CABG $(\%)$ & 10.5 & 10.0 & 1.00 & 10.3 \\
\hline Previous myocardial infarction (\%) & 86.8 & 70.0 & 0.23 & 81.0 \\
\hline Unstable angina $(\%)$ & 44.7 & 40.0 & 0.95 & 43.1 \\
\hline Duration of angina (months) & $0.9 \pm 0.8$ & $2.5 \pm 3.8$ & 0.09 & $1.6 \pm 2.5$ \\
\hline Main vessel disease (\%) & 28.9 & 30.0 & 1.00 & 29.3 \\
\hline Number of diseased vessels & $2.4 \pm 0.7$ & $2.8 \pm 0.4$ & 0.005 & $2.6 \pm 0.6$ \\
\hline Chronic kidney disease (\%) & 31.6 & 30.0 & 1.00 & 31.0 \\
\hline \multicolumn{5}{|l|}{$\underline{\text { Chronic heart failure }}$} \\
\hline NYHA functional class II (\%) & 71.1 & 80.0 & 0.67 & 74.1 \\
\hline NYHA functional class III (\%) & 28.9 & 20.0 & 0.67 & 25.9 \\
\hline Previous stroke $(\%)$ & 10.5 & 10.0 & 1.00 & 10.3 \\
\hline Hyperlipidemia (\%) & 86.8 & 80.0 & 0.76 & 84.5 \\
\hline Smoking (\%) & 60.5 & 45.0 & 0.39 & 55.2 \\
\hline Alcohol abuse (\%) & 2.6 & 5.0 & 1.00 & 3.4 \\
\hline
\end{tabular}

* For the comparison between patients who underwent on-pump and those who underwent off-pump CABG.

Table 2. Clinical and Laboratory Findings at Admission (Mean \pm SD)

\begin{tabular}{|c|c|c|c|c|}
\hline Systolic BP (mmHg) & $120.1 \pm 17.4$ & $133.8 \pm 16.3$ & 0.005 & $124.9 \pm 18.1$ \\
\hline Pulse rate (beats/min) & $73.2 \pm 9.1$ & $73.4 \pm 8.3$ & 0.94 & $73.2 \pm 8.7$ \\
\hline Body mass index $\left(\mathrm{kg} / \mathrm{m}^{2}\right)$ & $28.3 \pm 4.2$ & $27.2 \pm 2.9$ & 0.34 & $27.9 \pm 3.9$ \\
\hline Total cholesterol (mg/dl) & $173.7 \pm 41.8$ & $175.8 \pm 58.7$ & 0.87 & $174.4 \pm 47.8$ \\
\hline LDL cholesterol (mg/dl) & $109.7 \pm 35.9$ & $110.6 \pm 57.7$ & 0.94 & $110.0 \pm 44.1$ \\
\hline HDL cholesterol (mg/dl) & $36.5 \pm 9.4$ & $40.0 \pm 10.2$ & 0.19 & $37.7 \pm 9.7$ \\
\hline Triglycerides (mg/dl) & $137.6 \pm 47.2$ & $124.3 \pm 57.3$ & 0.35 & $133.0 \pm 50.8$ \\
\hline Uric acid (mg/dl) & $7.1 \pm 1.9$ & $6.1 \pm 1.1$ & 0.043 & $6.7 \pm 1.7$ \\
\hline Fibrinogen $(\mathrm{mg} / \mathrm{dl})$ & $398.0 \pm 76.4$ & $376.7 \pm 88.3$ & 0.38 & $389.4 \pm 81.1$ \\
\hline BNP (median (range) $)(\mathrm{ng} / \mathrm{ml})$ & $1.2(0.1-64.2)$ & $0.8(0.1-7.1)$ & 0.08 & $1.0(0.1-64.2)$ \\
\hline
\end{tabular}

*For the comparison between patients who underwent on-pump and those who underwent off-pump CABG. 
$\mathrm{p}=0.022)$, cardiac index $(\mathrm{r}=-0.281, \mathrm{p}=0.048)$, and LVDd $(\mathrm{r}=0.283, \mathrm{p}=0.033)$. In addition, preoperative BNP levels showed significant negative correlation with preoperative LVEF, as determined both by echocardiogram and during ventriculography $(r=-0.392, p=0.003$ and $r=-0.451, p=0.004$, respectively).

Complete revascularization was achieved in all patients. Two patients $(3.4 \%)$ had a single coronary graft, 19 had two grafts $(32.8 \%), 34$ had three grafts $(58.6 \%)$, and three had four grafts $(5.2 \%)$. Intraoperative and postoperative complications are summarized in Tables $\mathbf{3}$ and $\mathbf{4}$ respectively. There were no significant differences in the rate of complications between patients undergoing on-pump or off-pump CABG. None of the patients suffered a required reoperation, and none required readmission within the follow-up period. There were four hospital deaths. In the on-pump CABG group, two patients died $(5.3 \%)$, five and 68 days postoperatively respectively, because of septic shock and multiorganic failure respectively. In the off-pump CABG group, two patients died $(10.0 \%)$, three and 16 days postoperatively respectively, because of ventricular fibrillation and septic shock respectively. Among the patients who left the hospital, none died within 30 days after surgery.

In both patients in the on-pump and off-pump CABG groups, BNP changed significantly postoperatively $(\mathrm{p}<0.0005$ and $\mathrm{p}=0.025$ respectively) (Fig. 1). In the group undergoing on-pump $\mathrm{CABG}, \mathrm{BNP}$ concentrations increased progressively and reached their peak on the third day after the operation to $2.51 \mathrm{ng} / \mathrm{ml}$ (range, $0.1-19.43 \mathrm{ng} / \mathrm{ml}, \mathrm{p}=0.027$ compared to preoperative levels), decreased gradually thereafter, but remained above baseline levels the thirtieth day after CABG (Fig. 1). In contrast, in the group undergoing off-pump CABG, BNP concentrations decreased immediately after $\mathrm{CABG}$, albeit not significantly, increased gradually thereafter, also reaching highest values the third day after the operation to $1.62 \mathrm{ng} / \mathrm{ml}$ (range, $0.1-8.22 \mathrm{ng} / \mathrm{ml}$,

Table 3. Number of Patients who Experienced Intraoperative Complications

\begin{tabular}{|l|c|c|c|c|}
\hline \multicolumn{1}{|c|}{ Parameter } & On-Pump CABG (n=38) & Off-Pump CABG (n=20) & p* & Overall (n=58) \\
\hline \hline Arrhythmia & 2 & 3 & 0.44 & 5 \\
\hline Intra-aortic balloon pump & 1 & 3 & 0.22 & 4 \\
\hline Cardiogenic shock & 0 & 1 & 0.74 & 1 \\
\hline Dopamine $>3 \mu \mathrm{g} / \mathrm{kg} / \mathrm{min}(\%)$ & 2 & 1 & 1.00 & 3 \\
\hline Epinephrine (\%) & 13 & 11 & 0.21 & 1.00 \\
\hline Milrinone (\%) & 10 & 6 & 24 \\
\hline
\end{tabular}

* For the comparison between patients who underwent on-pump and those who underwent off-pump CABG.

Table 4. Number of Patients who Experienced Postoperative Complications

\begin{tabular}{|c|c|c|c|c|}
\hline Parameter & On-Pump CABG $(\mathrm{n}=38)$ & Off-Pump CABG $(n=20)$ & $\mathbf{p}^{*}$ & Overall $(n=58)$ \\
\hline Non-ST segment elevation myocardial infarction & 1 & 0 & 1.00 & 1 \\
\hline Cardiac enzyme elevation & 2 & 2 & 0.89 & 4 \\
\hline Cardiorespiratory arrest & 1 & 1 & 1.00 & 2 \\
\hline Arrhythmia & 11 & 5 & 0.99 & 16 \\
\hline Defibrillation & 0 & 1 & 0.74 & 1 \\
\hline Inotropic support & 33 & 16 & 0.76 & 49 \\
\hline Intra-aortic balloon pump & 2 & 3 & 0.44 & 5 \\
\hline Cardiogenic shock & 2 & 0 & 0.77 & 2 \\
\hline Pleural effusion & 10 & 5 & 1.00 & 15 \\
\hline Reintubation & 3 & 2 & 1.00 & 5 \\
\hline Acute respiratory failure & 5 & 1 & 0.61 & 6 \\
\hline Acute renal failure & 1 & 0 & 1.00 & 1 \\
\hline Ventilator dependence $>24$ hours & 3 & 2 & 1.00 & 5 \\
\hline Intensive care unit length of stay $>3$ days & 7 & 2 & 0.64 & 9 \\
\hline Total hospital length of stay $>9$ days & 9 & 4 & 1.00 & 13 \\
\hline Death & 2 & 2 & 0.89 & 4 \\
\hline
\end{tabular}

* For the comparison between patients who underwent on-pump and those who underwent off-pump CABG. 


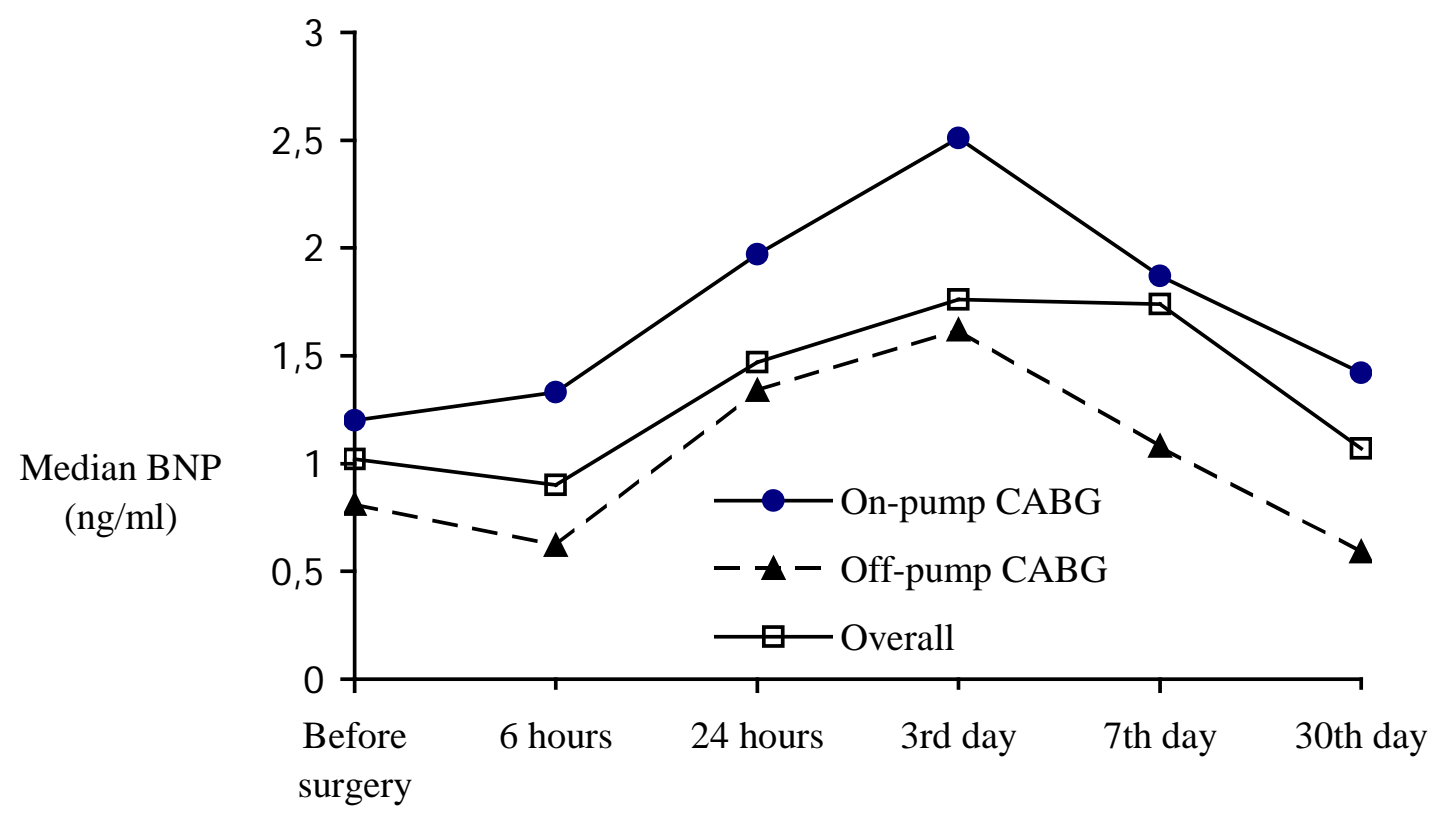

Fig. (1). Time courses of brain natriuretic peptide (BNP) concentration in patients undergoing on-pump CABG, off-pump CABG, and overall (median values).

$\mathrm{p}=0.032$ compared to preoperative levels), and decreased progressively thereafter to levels lower than baseline levels the thirtieth day after CABG (Fig. 1). In both groups, preoperative BNP levels and BNP levels at the thirtieth postoperative day did not differ significantly. In both groups, there was a very strong correlation between baseline BNP levels and BNP values at all time points. However, the differences in BNP levels between the two patient groups were not significant at any time point. Furthermore, the postoperative time course of BNP concentration was independent of the number of diseased vessels.

Duration of ventilation dependence and postoperative days spent in the ICU significantly correlated with preoperative BNP levels $(\mathrm{r}=0.339, \mathrm{p}=0.01$ and $\mathrm{r}=0.266, \mathrm{p}=0.045$ respectively). In univariate analysis, preoperative BNP concentration predicted the occurrence of four major postoperative complications: requirement of inotropic support, cardiogenic shock, reintubation, and death. Except preoperative BNP concentrations, LVDd was the only other parameter associated with a higher risk of postoperative requirement of inotropic support in univariate analysis. However, in multivariate analysis, only LVDd was found to be an independent predictor of postoperative requirement of inotropic support with an odds ratio of 24.15 (95\% confidence interval, 2.04286.47; $\mathrm{p}=0.012$ ). Regarding cardiogenic shock, preoperative BNP concentration was the only independent predictor with an odds ratio of 26.83 (95\% confidence interval, 1.22590.97; $\mathrm{p}=0.037$ ). Regarding reintubation, in univariate analysis, age, COPD, chronic kidney disease, and NYHA class III showed predictive value. Nevertheless, in multivariate analysis, none of these parameters was independently associated with reintubation. Finally, regarding mortality, in univariate analysis, presence of COPD was the only other parameter besides preoperative BNP concentration associated with a higher risk of death. In multivariate analysis, both these parameters were associated with mortality; preoperative BNP concentration with an odds ratio of 13.58 (95\% confidence interval, 1.29-142.76; $\mathrm{p}=0.030$ ) and COPD with an odds ratio of 53.94 (95\% confidence interval, 2.271281.37; $\mathrm{p}=0.014)$. Preoperative BNP concentration could not predict other postoperative complications, neither any of the intraoperative complications. In addition, postoperative BNP concentrations could not predict any postoperative complication. In a separate analysis according to type of CABG, among patients who underwent on-pump CABG, preoperative BNP concentration was the only parameter that could predict mortality with an odds ratio of $30.08(95 \%$ confidence interval, 1.01-898.87; $\mathrm{p}=0.050)$, whereas in the off-pump CABG group preoperative BNP levels had no predictive value, possibly due to the small number of patients in this group.

The ROC curves for BNP as a predictor of postoperative requirement of inotropic support, development of cardiogenic shock, requirement of reintubation, and mortality, had areas under the curve of $0.701,0.900,0.777$ and 0.774 respectively. A preoperative BNP of $2.1 \mathrm{pg} / \mathrm{ml}$ had a sensitivity of $33 \%, 100 \%, 80 \%$, and $75 \%$ and a specificity of $89 \%$, $73 \%, 75 \%$, and $74 \%$ for predicting the postoperative requirement of inotropic support, development of cardiogenic shock, reintubation, and mortality respectively.

Compared with pre-CABG assessment, LVEF increased significantly as early as 7 days postoperatively $(41.8 \pm 8.5 \%$, $\mathrm{p}<0.0005$ compared to preoperative levels) and even more at 30 days post-CABG $(47.9 \pm 9.1 \%, \mathrm{p}<0.0005$ compared to preoperative levels and $\mathrm{p}=0.005$ compared to $\mathrm{LVEF}$ levels at $7^{\text {th }}$ day) (Fig. 2). Patients who underwent off-pump CABG showed greater increases in LVEF at the $30^{\text {th }}$ postoperative day compared to the ones who underwent on-pump CABG $(53.2 \pm 7.8 \%$ vs $45.5 \pm 8.7 \%$, $\mathrm{p}<0.0005)$. Neither preoperative nor postoperative BNP levels could identify the patients that showed improvement in LVEF. Finally, lower preoperative LVEF, as determined by echocardiography, predicted the need for prolonged stay in the ICU postoperatively in univariate analysis, and so did previous $\mathrm{CABG}$, previous stroke, 


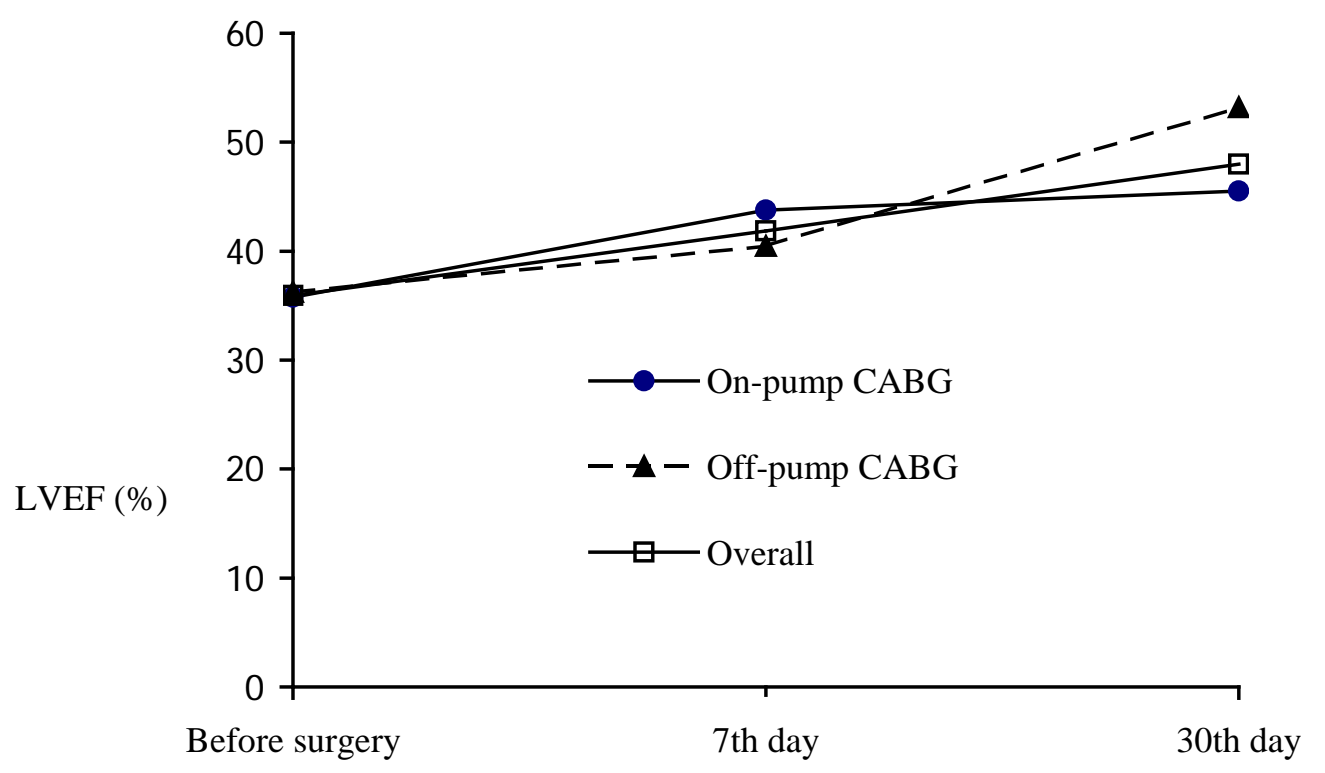

Fig. (2). Time courses of left ventricular ejection fraction (LVEF) in patients undergoing on-pump CABG, off-pump CABG, and overall (mean $\pm \mathrm{SD})$.

presence of atrial fibrillation preoperatively, and lower creatinine clearance. However, in multivariate analysis, none of these parameters could independently predict the occurrence of this complication.

The postoperative secretion pattern of CK-MB was independent of the type of CABG (Fig. 3). Furthermore, CK-MB values did not correlate with identically timed BNP concentrations and more importantly, did not show significant independent prognostic value for any postoperative complication.

\section{DISCUSSION}

The main finding of this study is that, in patients with $\mathrm{CAD}$ and ischemic heart failure undergoing CABG, preoperative BNP levels independently predict the occurrence of cardiogenic shock and more importantly, short-term mortality.

The principal physiological effects of BNP include natriuresis, vasodilatation, and inhibition of renin-angiotensinaldosterone system and sympathetic outflow [24,25]. Several recent studies have demonstrated that $\mathrm{BNP}$ is a reliable index of LV dysfunction [26-29], and thus BNP has emerged as a key biomarker for the diagnosis, evaluation and management of congestive heart failure [43]. In the present study, plasma BNP showed significant negative correlation with preoperative EF, as determined both by echocardiogram and during ventriculography, and with cardiac index, which is consistent with the data reported by other investigators [26-29]. Therefore, it seems logical that preoperative BNP could be capable

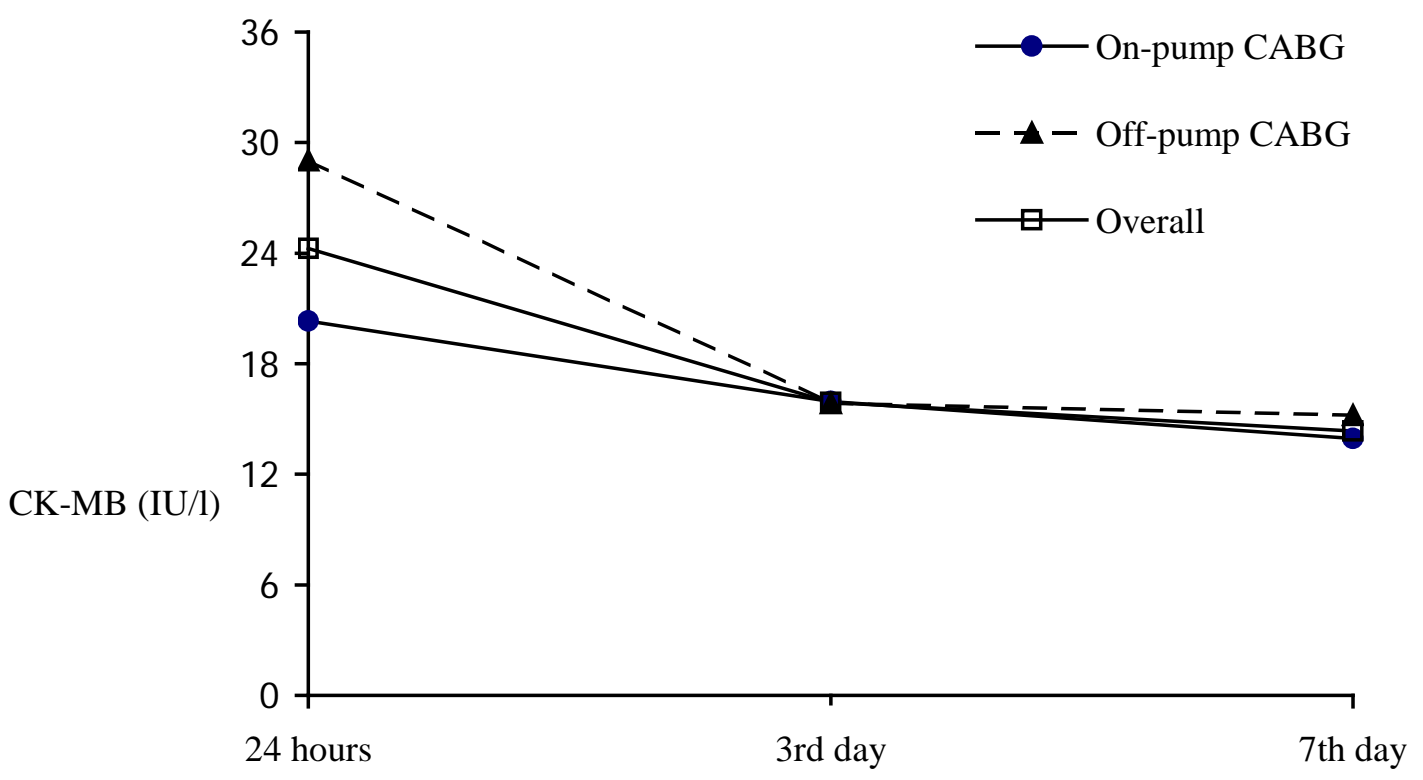

Fig. (3). Secretion patterns of creatine phosphokinase myocardial band (CK-MB) in patients undergoing on-pump CABG, off-pump CABG, and overall (mean \pm SD). 
of predicting postoperative outcomes.

Our data confirm the predictive power of BNP and its potential prognostic role. Increased preoperative BNP concentrations predicted postoperative morbidity and mortality, in agreement with previous reports [23,30-35]. Cardiac dysfunction is a frequent complication of $\mathrm{CABG}$, results from cardioplegia and $\mathrm{CPB}$, as well as from ongoing ischaemia, and worsens the patients' prognosis [44]. Our results demonstrate that a lot of patients undergoing CABG develop LV dysfunction, manifesting either as hemodynamic instability requiring inotropic support or, less frequently, as cardiogenic shock. Risk stratification is therefore an important issue in these patients. A limited number of reports suggest that the occurrence of acute heart failure after cardiac surgery can be predicted by the preoperative BNP concentration [30,31], and this was evident in this study as well. But even more importantly, preoperative BNP concentrations predicted increased mortality during short-term follow-up, providing additional evidence to the available scant data [23,32]. The odds ratio in our study are characterized by rather wide confidence intervals; the low rate of complications and the relatively small number of patients are the most likely explanations for this finding, but does not necessarily compromise the predictive significance of preoperative BNP levels. Finally, since postoperative BNP concentration reflects perioperative cardiac injury $[15,45]$, in certain studies postoperative BNP concentration was better predictor for the occurrence of post-CABG complications than preoperative BNP concentration [15,23,33], although other authors have reported opposite findings [32,34]. However, postoperative BNP levels did not carry significant predictive value in our study.

Low LVEF alone has been reported to represent one of the best independent predictors of postoperative morbidity and mortality [14,15]. However, other authors have shown that preoperative LVEF does not have significant predictive value [23]. In our study group as well, LVEF, although showing significant correlation with preoperative BNP levels, could not predict any postoperative complications, in striking contrast with BNP. In addition, preoperative functional status reflected by NYHA class did not have any predictive value as well.

The usefulness of CK-MB as a reliable marker of perioperative myocardial ischaemia and injury after CABG, both on-pump and off-pump, has been demonstrated [46,47]. There is growing evidence that even small elevations of CK$\mathrm{MB}$ in the periprocedural period are independently associated with a significant increase in myocardial infarction, postoperative LV dysfunction and both early and late mortality [16-22]. One might speculate that the combination of a necrosis marker - such as CK-MB - and a volume and pressure marker - such as BNP - might be useful for further risk stratification of patients before and in the early postoperative state. However, this was not apparent in our study and postoperative CK-MB concentrations did not exhibit significant predictive value. Thus, our data do not support routine use of CK-MB measurement following CABG to further delineate short-term risk of complications.

In the present study, we have also evaluated the behaviour of BNP levels secondary to CABG. In agreement with several previous reports [15,31-33,44,48-50], we observed a marked and systematic postoperative increase of BNP levels, reaching a peak 3 days post-CABG. It has also been reported that BNP release is enhanced not only in the early phase after CABG but also after as late as one week postoperatively $[31,49]$, and this was observed in our study as well. Moreover, increased BNP levels tended to return to the baseline values as early as 30 days from cardiac surgery, in accordance to previous reports [31]. Other studies however, have showed more delayed reductions in BNP levels after revascularization, from 3 to 10 months of follow up [49,51]. Lack of more early determinations of BNP concentration and differences in the study population might account for these discrepant results. Regarding the effect of $\mathrm{CPB}$ on the time course of BNP concentration, there is a paucity of relevant data $[34,35,50,52]$. In two recent studies in patients undergoing off-pump CABG, BNP concentrations peaked $48 \mathrm{~h}$ after surgery and began to decrease at $72 \mathrm{~h}$, similarly to our findings $[34,35]$. In our comparative study, in accordance to a previous one [50], postoperative BNP levels did not differ significantly between patients undergoing on-pump or offpump CABG. The elevation of BNP level lasted longer in the on-pump CABG group, however this difference was not significant.

The pathophysiology of increased production of BNP post-CABG is unclear. It may result from acute left ventricular dysfunction and also relate to increased preload on the heart resulting from increased intravascular volume or transient diastolic dysfunction [15,32,50]. In addition, it is well established that ischemic insult constitutes an independent stimulus for BNP release even in the absence of LV dysfunction [32,53-56]. It has thus been suggested that BNP stimulation in $\mathrm{CABG}$ patients may be due to the augmented regional wall stretch induced by perioperative myocardial ischemia [2,32]. It has also been demonstrated that patients with significant myocardial damage have higher BNP levels [15]. However, in certain studies, including ours, BNP concentrations did not correlate with CK-MB levels, suggesting that the degree of myocardial necrosis post-CABG is insufficient to affect ventricular function and circulating BNP concentrations $[33,50]$. In addition, and in contrast to previous reports $[49,57]$, patients with more extensive CAD did not exhibit higher BNP levels postoperatively. Finally, it must be emphasized that BNP release, except from constituting a marker of vascular and myocyte injury, also represents a counterregulatory system for protection of cardiac muscle [25]. Thus, postoperative increase of BNP might not reflect a state of acute perioperative heart failure or myocardial damage [48]. The lack of predictive value of postoperative BNP levels regarding the occurrence of complications further supports this assumption.

It is well established that $\mathrm{CPB}$, presumably because of the blood's contact with foreign materials and its exposure to abnormal shear forces [58], causes an increase of circulating cathecholamines and endothelin, augments oxidative stress, activates the coagulation, fibrinolytic, kallikrein, and complement cascades and may enhance the postoperative inflammatory response [1-5]. Furthermore, cardiac operations with $\mathrm{CPB}$ result in heart ischemia during the period of heart arrest, while heart reperfusion after this ischemic period produces myocardial damage and eventual necrosis [59]. Finally, CPB produces numerous other important causes of myocardial damage, including atriotomy, poor myocardial 
protection, and myocardial stunning [15,59]. In contrast, CABG without using extra-corporeal circulation is associated with reduced cytokine responses, decreased oxidative stress, and less ischemic and reperfusion myocardial injury [3-6,50,59-61]. Indeed, a number of studies have shown that patients operated with CPB had more circulating CK-MB postoperatively than patients operated off-pump, suggesting a reduced myocardial cell damage with off-pump CABG [7,10,11,47,50,59,62-64]. More importantly, recent randomized studies comparing the two techniques, showed comparable cardiac outcome [7-11] and reduced perioperative myocardial infarction, reduced postoperative bleeding, preservation of renal function, lower surgical reexploration rates, shortened hospital stays, economical advantages, and decreased operative mortality [7-13,65]. In this relatively small study, we could not identify significant differences in CK$\mathrm{MB}$ release or, more importantly, in the occurrence of complications between patients undergoing on-pump or offpump CABG. However, it must be noted that patients in the on-pump group had more favourable preoperative characteristics and this might have contributed to this lack of differences between groups.

$\mathrm{CABG}$ is being performed with increasing frequency in patients with severe LV dysfunction with favorable results $[66,67]$. This is based on the finding that in many patients with CAD, impairment of LV function is not always irreversible, since it results from the presence of viable, hibernating myocardium, rather than of irreversible fibrosis [68]. The important characteristic of hibernating myocardium is its ability to improve its contractile function after myocardial revascularization [69]. The results of this study are in agreement with the above-cited reports $[66,67]$, and show that patients with compromised LV function have significant improvement of LVEF, as well as good in-hospital outcomes and medium-term survival. In this study of patients with CAD and LV dysfunction, plasma BNP concentrations were increased in proportion to the degree of hemodynamic impairment, whereas a decrement was observed after coronary revascularization, which paralleled the significant improvement of LV function. It has previously been demonstrated that preoperative plasma levels of BNP could predict the post-CABG recovery of the LV function [51]; however, in this study neither preoperative nor postoperative BNP levels could predict this favorable outcome.

Our study has several limitations. We studied only 58 patients and among them only 2 were women. Therefore, the statistical power to identify predictors for adverse early outcomes was insufficient. This might explain why neither LVEF nor CK-MB levels predicted outcome in our study, in contrast to previous larger studies. We chose this approach because the existing data on the predictive value of preoperative BNP levels in patients undergoing CABG are limited. We therefore conducted this pilot study to gain more insight on the topic. Another limitation is that patients were not randomly allocated to on-pump or off-pump CABG. This is an important bias which could affect the results. Finally, the mortality rates in our cohort were quite high and this might reflect the characteristics of our study population (i.e. patients with CAD and ischemic heart failure). Therefore, our findings might not apply to all patients undergoing CABG.

\section{CONCLUSION}

Preoperative BNP levels have considerable predictive value in patients with $\mathrm{CAD}$ and ischemic heart failure undergoing $\mathrm{CABG}$. Our results also suggest that it may be prudent to more closely monitor patients with higher preoperative BNP levels for possible postoperative complications. Further studies on larger and more diverse populations are warranted to compare predictive ability of preoperative BNP to currently applied factors and to evaluate potential for integration of this marker into preoperative evaluation. Preoperative BNP will probably need to be assessed in combination with other predictive factors (e.g. LVEF, CK-MB or troponin I) to improve risk stratification in patients undergoing CABG.

\begin{tabular}{|c|c|c|}
\hline \multicolumn{3}{|c|}{ ABBREVIATIONS } \\
\hline BNP & $=$ & Brain natriuretic peptide \\
\hline CABG & $=$ & Coronary artery bypass grafting surgery \\
\hline CK-MB & $=$ & Creatine phosphokinase myocardial band \\
\hline CAD & $=$ & Coronary artery disease \\
\hline $\mathrm{CPB}$ & $=$ & Cardiopulmonary bypass \\
\hline LVEF & $=$ & Left ventricular ejection fraction \\
\hline COPD & $=$ & Chronic obstructive pulmonary disease \\
\hline LDL-C & $=$ & Low-density lipoprotein cholesterol \\
\hline NYHA & $=$ & New York Heart Association \\
\hline HDL-C & $=$ & High-density lipoprotein cholesterol \\
\hline ELISA & $=$ & Enzyme-linked immunosorbent assay \\
\hline IVS & $=$ & Interventricular septal thickness \\
\hline PW & $=$ & Posterior wall thickness \\
\hline LVDd & $=$ & LV diameter at end-diastole \\
\hline $\mathrm{ICU}$ & $=$ & Intensive care unit \\
\hline ANOVA & $=$ & Analysis of variance \\
\hline ANCOVA & $=$ & Analysis of covariance \\
\hline OR & $=$ & Odds ratios \\
\hline $\mathrm{CI}$ & $=$ & Confidence intervals \\
\hline ROC & $=$ & Receiver operating characteristic \\
\hline
\end{tabular}

\section{REFERENCES}

[1] Czerny M, Baumer H, Kilo J, et al. Inflammatory response and myocardial injury following coronary artery bypass grafting with or without cardiopulmonary bypass. Eur J Cardiothorac Surg 2000; 17: 737-42.

[2] Mair P, Mair J, Bleier J, et al. Augmented release of brain natriuretic peptide during reperfusion of the human heart after cardioplegic cardiac arrest. Clin Chim Acta 1997; 261: 57-68.

[3] Wan IY, Arifi AA, Wan S, et al. Beating heart revascularization with or without cardiopulmonary bypass: evaluation of inflammatory response in a prospective randomized trial. $\mathrm{J}$ Thorac Cardiovasc Surg 2004; 127: 1624-31.

[4] Wan S, Izzat MB, Lee TW, et al. Avoiding cardiopulmonary bypass in multivessel CABG reduces cytokine response and myocardial injury. Ann Thorac Surg 1999; 68: 52-7.

[5] Schulze C, Conrad N, Schutz A, et al. Reduced expression of systemic proinflammatory cytokines after off-pump versus conventional coronary artery bypass grafting. Thorac Cardiovasc Surg 2000; 48: 364-9. 
[6] Ascione R, Lloyd CT, Underwood MJ, et al. Inflammatory response after coronary revascularization with or without cardiopulmonary bypass. Ann Thorac Surg 2000; 69: 1198-1204.

[7] van Dijk D, Nierich AP, Jansen EW, et al. Octopus Study Group. Early outcome after off-pump versus on-pump coronary bypass surgery. Results from a randomized study. Circulation 2001; 104: 1761-6.

[8] Nathoe HM, van Dijk D, Jansen EW, et al. Octopus Study Group. A comparison of on-pump and off-pump coronary bypass surgery in low-risk patients. N Engl J Med 2003; 348: 394-402.

[9] Angelini GD, Taylor FC, Reeves BC, Ascione R. Early and midterm outcome after off-pump and on-pump surgery in beating heart against cardioplegic arrest studies (BHACAS 1 and 2): a pooled analysis of two randomized controlled trials. Lancet 2002; 359: 1194-9.

[10] Puskas JD, Williams WH, Duke PG, et al. Off-pump coronary artery bypass grafting provides complete revascularization with reduced myocardial injury, transfusion requirements, and length of stay: a prospective randomized comparison of two hundred unselected patients undergoing off-pump versus conventional coronary artery bypass grafting. J Thorac Cardiovasc Surg 2003; 125: 797808.

[11] Khan NE, deSouza A, Mister R, et al. A randomized comparison of off-pump and on-pump multivessel coronary artery bypass surgery. N Engl J Med 2004; 350: 21-8.

[12] Ascione R, Williams S, Lloyd CT, et al. Reduced post-operative blood loss and transfusion requirement after beating-heart coronary operations: a prospective randomized study. J Thorac Cardiovasc Surg 2001; 121: 689-96.

[13] Ascione R, Lloyd CT, Underwood MJ, et al. On-pump versus offpump coronary revascularization. Evaluation of renal function. Ann Thorac Surg 1999; 68: 493-8.

[14] Magovern JA, Sakert T, Magovern GJ Jr., et al. A model that predicts morbidity and mortality after coronary artery bypass graft surgery. J Am Coll Cardiol 1996; 28: 1147-53.

[15] Provenchere S, Berroeta C, Reynaud C, et al. Plasma brain natriuretic peptide and cardiac troponin I concentrations after adult cardiac surgery: association with postoperative cardiac dysfunction and 1-year mortality. Crit Care Med 2006; 34: 995-1000.

[16] Costa MA, Carere RG, Lichtenstein SV, et al. Incidence, predictors, and significance of abnormal cardiac enzyme rise in patients treated with bypass surgery in the arterial revascularization therapies study (ARTS). Circulation 2001; 104: 2689-93.

[17] Klatte K, Chaitman BR, Theroux P, et al. Guardian Investigators (The GUARD during Ischemia Against Necrosis). Increased mortality after coronary artery bypass graft surgery is associated with increased levels of postoperative creatine kinase-myocardial band isoenzyme release: results from the guardian trial. J Am Coll Cardiol 2001; 38: 1070-7.

[18] Marso SP, Bliven BD, House JA, et al. Myonecrosis following isolated coronary artery bypass grafting is common and associated with an increased risk of long-term mortality. Eur Heart J 2003; 24: 1323-8.

[19] Steuer J, Horte LG, Lindahl B, Stahle E. Impact of perioperative myocardial injury on early and long-term outcome after coronary artery bypass grafting. Eur Heart J 2002; 23: 1219-27.

[20] Brener SJ, Lytle BW, Schneider JP, et al. Association between CKMB elevation after percutaneous or surgical revascularization and three-year mortality. J Am Coll Cardiol 2002; 40: 1961-7.

[21] Engoren MC, Habib RH, Zacharias A, et al. The association of elevated creatine kinase-myocardial band on mortality after coronary artery bypass grafting surgery is time and magnitude limited. Eur J Cardiothorac Surg 2005; 28: 114-9.

[22] Ramsay J, Shernan S, Fitch J, et al. Increased creatine kinase MK level predicts postoperative mortality after cardiac surgery independent of new Q waves. J Thorac Cardiovasc Surg 2005; 129: 300-6.

[23] Hutfless R, Kazanegra R, Madani M, et al. Utility of B-type natriuretic peptide in predicting postoperative complications and outcomes in patients undergoing heart surgery. J Am Coll Cardiol 2004; 43: 1873-9.

[24] Levin ER, Gardner DG, Samson WK. Natriuretic peptides. N Engl J Med 1998; 339: 321-8.

[25] Stein BC, Levine RI. Natriuretic peptides: physiology, therapeutic potential, and risk stratification in ischaemic heart disease. Am Heart J 1998; 135: 914-23.
[26] Maisel AS, Koon J, Krishnaswamy P, et al. Utility of B-natriuretic peptide as a rapid, point-of-care test for screening patients undergoing echocardiography to determine left ventricular dysfunction. Am Heart J 2001; 141: 367-74.

[27] Krishnaswamy P, Lubien E, Clopton P, et al. Utility of Bnatriuretic peptide levels in identifying patients with left ventricular systolic or diastolic dysfunction. Am J Med 2001; 111: 274-9.

[28] McDonagh TA, Robb SD, Murdoch DR, et al. Biochemical detection of left-ventricular systolic dysfunction. Lancet 1998; 351: 913.

[29] Karagiannis A, Tziomalos K, Zamboulis C. Plasma B-type natriuretic peptide is related to left ventricular mass in hypertensive patients. Eur Heart J 2004; 25: 1967.

[30] Cuthbertson BH, McKeown A, Croal BL, et al. Utility of B-type natriuretic peptide in predicting the level of peri- and postoperative cardiovascular support required after coronary artery bypass grafting. Crit Care Med 2005; 33: 437-42.

[31] Morimoto K, Mori T, Ishiguro S, Matsuda N, Hara Y, Kuroda H. Perioperative changes in plasma brain natriuretic peptide concentrations in patients undergoing cardiac surgery. Surg Today 1998; 28: 23-9.

[32] Berendes E, Schmidt C, Van Aken H, et al. A-type and B-type natriuretic peptides in cardiac surgical procedures. Anesth Analg 2004; 98: 11-9.

[33] Watanabe M, Egi K, Hasegawa S, et al. Significance of serum atrial and brain natriuretic peptide release after coronary artery bypass grafting. Surg Today 2003; 33: 671-3.

[34] Kerbaul F, Collart F, Giorgi R, et al. Increased plasma levels of pro-brain natriuretic peptide in patients with cardiovascular complications following off-pump coronary artery surgery. Intensive Care Med 2004; 30: 1799-1806.

[35] Kerbaul F, Giorgi R, Oddoze C, et al. High concentrations of NBNP are related to non-infectious severe SIRS associated with cardiovascular dysfunction occurring after off-pump coronary artery surgery. Br J Anaesth 2004; 93: 639-44.

[36] Brosius FC, Hostetter TH, Kelepouris E, et al. Detection of chronic kidney disease in patients with or at increased risk of cardiovascular disease. Circulation 2006; 114: 1083-7.

[37] Friedewald WT, Levy RI, Fredrickson DS. Estimation of the concentration of low-density lipoprotein cholesterol in plasma, without use of the preparative ultracentrifuge. Clin Chem 1972; 18: 499502 .

[38] Porstmann T, Kiessig ST. Enzyme immunoassay techniques. An overview. J Immunol Methods 1992; 150: 5-21.

[39] Avrameas S. Amplification systems in immunoenzymatic techniques. J Immunol Methods 1992; 150: 23-32.

[40] Teichholz LE, Kreulen T, Herman MV, Gorlin R. Problems in echocardiographic volume determinations: echocardiographicangiographic correlations in the presence of absence of asynergy. Am J Cardiol 1976; 37: 7-11.

[41] Caputo M, Bryan AJ, Calafiore AM, Suleiman MS, Angelini GD. Intermittent antegrade hyperkalaemic warm blood cardioplegia supplemented with magnesium prevents myocardial substrate derangement in patients undergoing coronary artery bypass surgery. Eur J Cardiothorac Surg 1998; 14: 596-601.

[42] Pitsis AA, Angelini GD. Off pump coronary bypass grafting of the circumflex artery. Eur J Cardiothorac Surg 1999; 16: 478-9.

[43] Cowie MR, Jourdain P, Maisel A, et al. Clinical applications of Btype natriuretic peptide (BNP) testing. Eur Heart J 2003; 24: 17108.

[44] Cosgrave J, Foley JB, McGovern E, et al. Brain natriuretic peptide elevation and the development of atrial fibrillation following coronary artery bypass surgery. Interact Cardiovasc Thorac Surg 2006; 5: 111-4

[45] Shimada Y, Yaku H, Shuntoh K, et al. Impact of myocardial angiotensin-converting enzyme activity on coronary vascular resistance and serum brain natriuretic peptide concentration in coronary bypass surgery. Circ J 2003; 67: 379-83.

[46] Hake U, Iversen S, Sadony V, et al. Diagnosis of perioperative myocardial necrosis following coronary artery surgery-a reappraisal of isoenzyme analysis. Eur J Cardiothorac Surg 1990; 4: 7984.

[47] Peivandi AA, Dahm M, Hake U, et al. Patterns and diagnostic value of cardiac troponin I $v s$ troponin $\mathrm{T}$ and $\mathrm{CKMB}$ after OPCAB surgery. Thorac Cardiovasc Surg 2001; 49: 137-43. 
[48] Bail DH, Kofler M, Ziemer G. Brain natriuretic peptide (BNP) in patients undergoing coronary artery bypass grafting. Thorac Cardiovasc Surg 2004; 52: 135-40.

[49] Palazzuoli A, Carrera A, Calabria P, et al. Brain natriuretic peptide levels during cardiac reperfusion: comparison between percutaneous coronary angioplasty and aorto-coronaric bypass. Clin Chim Acta 2004; 342: 87-92.

[50] Masuda M, Morita S, Tomita H, et al. Off-pump CABG attenuates myocardial enzyme leakage but not postoperative brain natriuretic peptide secretion. Ann Thorac Cardiovasc Surg 2002; 8: 139-44.

[51] Chello M, Mastroroberto P, Perticone F, et al. Plasma levels of atrial and brain natriuretic peptides as indicators of recovery of left ventricular systolic function after coronary artery bypass. Eur J Cardiothorac Surg 2001; 20: 140-6.

[52] Rastan AJ, Bittner HB, Gummert JF, et al. On-pump beating heart versus off-pump coronary artery bypass surgery-evidence of pumpinduced myocardial injury. Eur J Cardiothorac Surg 2005; 27: 1057-64.

[53] De Lemos JA, Morrow DA, Bentley JH, et al. The prognostic value of B-type natriuretic peptide in patients with acute coronary syndromes. N Engl J Med 2001; 345: 1014-21.

[54] Kikuta K, Yasue H, Yoshimura M, et al. Increased plasma levels of B-type natriuretic peptide in patients with unstable angina. Am Heart J 1996; 132: 101-7.

[55] Sabatine MS, Morrow DA, de Lemos JA, et al. Multimarker approach to risk stratification in non-ST elevation acute coronary syndromes. Simultaneous assessment of troponin I, C-reactive protein, and B type natriuretic peptide. Circulation 2002; 105: 1760-3.

[56] Goetze JP, Christoffersen C, Perko M, et al. Increased cardiac BNP expression associated with myocardial ischemia. FASEB J 2003; 17: 1105-7.

[57] Nishikimi T, Mori Y, Ishimura K, et al. Association of plasma atrial natriuretic peptide, $\mathrm{N}$-terminal proatrial natriuretic peptide, and brain natriuretic peptide levels with coronary artery stenosis in patients with normal left ventricular systolic function. Am J Med 2004; 116: 517-23.

[58] Kirklin JW, Barratt-Boyes BG. In: Kirklin JW, Barratt-Boyes BG, Eds. Cardiac Surgery. 2nd ed. New York, Churchill Livingstone. 1993; 61-128.
[59] Crescenzi G, Cedrati V, Landoni G, et al. Cardiac biomarker release after $\mathrm{CABG}$ with different surgical techniques. J Cardiothorac Vasc Anesth 2004; 18: 34-7.

[60] Matata BM, Sosnowski AW, Galinanes M. Off-pump bypass graft operation significantly reduces oxidative stress and inflammation. Ann Thorac Surg 2000; 69: 785-91.

[61] Menasche P. The systemic factor: the comparative roles of cardiopulmonary bypass and off-pump surgery in the genesis of patient injury during and following cardiac surgery. Ann Thorac Surg 2001; 72: S2260-70.

[62] Thielmann M, Massoudy P, Marggraf G, et al. Impact of intraoperative myocardial cellular damage on early hemodynamics after off-pump versus on-pump coronary artery bypass surgery. Eur $\mathbf{J}$ Med Res 2005; 10: 218-26.

[63] Wildhirt SM, Schulze C, Conrad N, et al. Reduced myocardial cellular damage and lipid peroxidation in off-pump versus conventional coronary artery bypass grafting. Eur J Med Res 2000; 23: 222-8.

[64] Kuduvalli M, Newall N, Stott A, et al. Impact of avoiding cardiopulmonary bypass for coronary surgery on perioperative cardiac enzyme release and survival. Eur J Cardiothorac Surg 2006; 29: 729-35.

[65] Ascione R, Lloyd CT, Underwood MJ, et al. Economic outcome of off-pump coronary artery bypass surgery. A prospective randomized study. Ann Thorac Surg 1999; 68: 2237-42.

[66] Ascione R, Narayan P, Rogers CA, et al. Early and midterm clinical outcome in patients with severe left ventricular dysfunction undergoing coronary artery surgery. Ann Thorac Surg 2003; 76: 7939.

[67] Nishi H, Miyamoto S, Takanashi S, et al. Complete revascularization in patients with severe left ventricular dysfunction. Ann Thorac Cardiovasc Surg 2003; 9: 111-6.

[68] Kloner RA, Przyklenl K. Hibernation and stunning of the myocardium. N Engl J Med 1991; 325: 1877-9.

[69] Shivalkar B, Maes A, Borgers M, et al. Only hibernating myocardium invariably shows early recovery after coronary revascularization. Circulation 1996; 94: 308-15. 